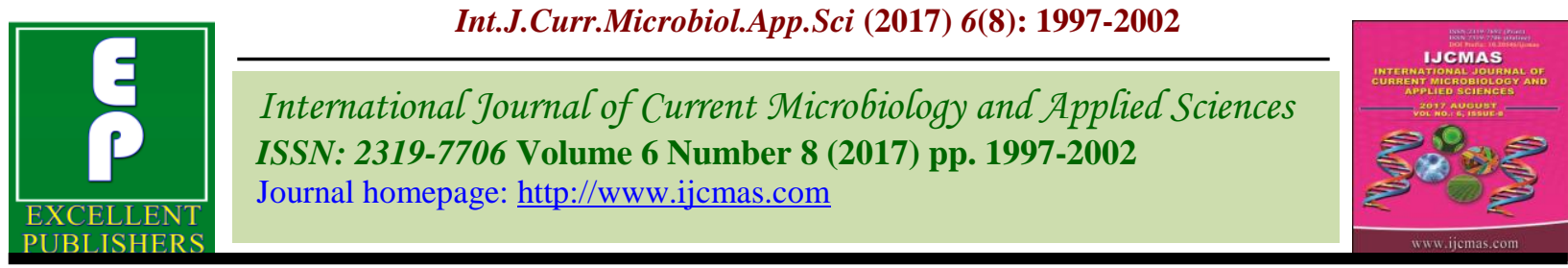

Original Research Article

https://doi.org/10.20546/ijcmas.2017.608.238

\title{
Studies on Carotenoid Content, Colour and Browning of Physio-Chemically Stored Mango (Mallika) Pulp for Processed Products
}

\author{
Manisha Jangir*, Virendra Singh and Disha Kala \\ Department of horticulture, Rajasthan College of Agriculture, Udaipur, Rajasthan, India \\ *Corresponding author
}

\begin{abstract}
A B S T R A C T
This study was carried out to evaluate the best preservation way for mango pulp preservation. For this the pulp of mango were preserved with thirteen different treatment combinations viz., pulp preserved with potassium meta-bisulphite $0.05 \%\left(\mathrm{~T}_{1}\right)$, pulp preserved with potassium meta-bisulphite $0.1 \%\left(\mathrm{~T}_{2}\right)$, pulp preserved with sodium benzoate $0.05 \%\left(\mathrm{~T}_{3}\right)$, pulp preserved with sodium benzoate $0.1 \%\left(\mathrm{~T}_{4}\right)$, pulp preserved with sodium meta-bisulphite $0.05 \%\left(\mathrm{~T}_{5}\right)$, pulp preserved with sodium meta bi-sulphite $0.1 \%\left(\mathrm{~T}_{6}\right)$, pulp preserved with potassium sorbate $0.05 \%\left(\mathrm{~T}_{7}\right)$, pulp preserved with potassium sorbate 0.1 $\%\left(\mathrm{~T}_{8}\right)$, pulp preserved with sodium benzoate + potassium sorbate $0.05 \%$ each $\left(\mathrm{T}_{9}\right)$, pulp preserved with potassium meta bi-sulphite + potassium sorbate $0.05 \%$ each $\left(\mathrm{T}_{10}\right)$, pulp preserved with sodium meta bi-sulphite + potassium sorbate $0.05 \%\left(\mathrm{~T}_{11}\right)$, refrigeration $4 \pm 2{ }^{\circ} \mathrm{C}\left(\mathrm{T}_{12}\right)$, frozen storage $-20^{\circ} \mathrm{C}\left(\mathrm{T}_{13}\right)$, These treatment combinations were evaluated under completely randomized design with four replications. The results revealed that low temperature $\left(-20{ }^{\circ} \mathrm{C}\right)$ storage was better with over all qualitative attributes viz., carotenoid content higher, browning lower and maintaining colour values. All parameters of samples were observed at fortnight interval during storage (up to 90 days) and at end of storage acceptable pulp were used for different products (RTS, Squash and jam) preparation and analyzed its quality. Statistical analysis showed that storage intervals and treatments had a significant $(\mathrm{P}<0.05)$ effect on carotenoid content, colour and browning of mango pulp.
\end{abstract}

Keywords

\section{Introduction}

Mango (Mangifera indica L.) is one of the most important fruit crops of India having socio-economic significance. It belongs to family Anacardiaceae and originated from South-East Asia. Mango ranks second after banana with annual production 185.05 million tons from an area of 22.16 million hectare with an average productivity of 7.3 MT. (Saxena et al., 2015). Mango fruit is widely accepted by consumers throughout the world for its succulence, sweet taste and exotic flavor, being called "The King of fruits". The fruits are consumed fresh and largely used in the food industry for the production of canned fruits, jam and concentrated juice (Tharanathan et al., 2006). The mango fruit is popular in international market due to its excellent flavour, attractive fragrance, beautiful colour, delicious taste and nutritional properties (Sivakumar et al., 2011).

Mango is a short seasoned fruit and being highly perishable does not withstand even in cold storage. Therefore, most of the fruit processing industries preserve mango pulp for the manufacture of mango products round the year. Mango pulp is not generally consumed 
directly rather used as fillings for pastries, jams, sauces, fruit juices and drinks (Hussain et al., 2003). The mango pulp is highly prone to microbial contamination due to high moisture content hence, pulp is having shortest shelf life. Therefore, the efforts have been made in the present investigation in order to improve the shelf life of mango pulp by using the various safe preservatives and with their optimum concentrations and temperature variations.

\section{Materials and Methods}

The experiment was carried out in PostHarvest Lab, Department of Horticulture, Rajasthan College of Agriculture, MPUAT, Udaipur (Rajasthan) during May to October, 2016. Fully mature and ripe mango $c v$. Mallika fruits procured from Agriculture Research Station, Banswara (Rajasthan) were used for experimentation. After bringing the fruits from the farm diseased, damaged and off type fruits were discarded. Fresh and physiologically mature mango fruits were washed with tap water to remove dirt and dust particles adhering to the surface of fruits and crushed for obtaining pulp. For the preservation of mango pulp, after washing, peeling and coring the flesh was cut into small pieces with stainless steel knives and pulp was made by using electric blender. After addition of water in 2:1, pulp was homogenized and passed through fine mesh to get uniform textured pulp. Pulp was then pasteurized in a water bath at a temperature of $82 \pm 2^{0} \mathrm{C}$ for 30 minutes to reduce the microbial load.

Obtained pulp was preserved with thirteen different treatments namely, pulp preserved with potassium meta-bisulphite $0.05 \%\left(\mathrm{~T}_{1}\right)$, pulp preserved with potassium metabisulphite $0.1 \%\left(\mathrm{~T}_{2}\right)$, pulp preserved with sodium benzoate $0.05 \%\left(\mathrm{~T}_{3}\right)$, pulp preserved with sodium benzoate $0.1 \% \quad\left(\mathrm{~T}_{4}\right)$, pulp preserved with sodium meta-bisulphite $0.05 \%$ $\left(\mathrm{T}_{5}\right)$, pulp preserved with sodium meta bisulphite $0.1 \% \quad\left(\mathrm{~T}_{6}\right)$, pulp preserved with potassium sorbate $0.05 \%\left(\mathrm{~T}_{7}\right)$, pulp preserved with potassium sorbate $0.1 \%\left(\mathrm{~T}_{8}\right)$, pulp preserved with sodium benzoate + potassium sorbate $0.05 \%$ each $\left(\mathrm{T}_{9}\right)$, pulp preserved with potassium meta bi-sulphite + potassium sorbate $0.05 \%$ each $\left(\mathrm{T}_{10}\right)$, pulp preserved with sodium meta bi-sulphite + potassium sorbate $0.05 \% \quad\left(\mathrm{~T}_{11}\right)$, refrigeration $4 \pm 2^{0} \mathrm{C}$ $\left(\mathrm{T}_{12}\right)$, frozen storage $-20^{\circ} \mathrm{C} \quad\left(\mathrm{T}_{13}\right)$ and replicated thrice. Physico-chemical parameters of samples were observed at 0,15 , $30,45,60,75,90$ days of storage. For carotenoid content of pulp, the Pulp was mixed with 80 per cent aqueous acetone for 2 hours at $50^{\circ} \mathrm{C}$ using an orbital shaker. Then it was filtered through Whatman paper. Filtrate was kept at $-20^{\circ} \mathrm{C}$ prior to analysis. $5 \mathrm{ml}$ of sample was mixed with $5 \mathrm{ml}$ distill water and $1 \mathrm{ml}$ of $\operatorname{mix}$ (hexane/acetone/methanol) (50/25/25 v/v). Sample was kept at centrifuge @ $3000 \mathrm{rpm}$ for 10 minutes. The absorbance of upper layer was measured at $450 \mathrm{~nm}$. Total carotenoid of the sample was calculated as $\mathrm{mg}$ $100 \mathrm{~g}^{-1}$ (Thimmiah, 1999).

\section{$\mathrm{A}_{\mathrm{n}} \times$ volume extract}

Total carotenoids

$\left(\mathrm{mg} 100 \mathrm{~g}^{-1}\right)=$

$$
\mathrm{A}^{\mathrm{x}} \times \text { sample weight }
$$

Where,

$\mathrm{A}_{\mathrm{n}}=$ Absorbance

$\mathrm{A}^{\mathrm{x}}=$ Absorbance coefficient (2505)

The colour parameters of mango pulp was measured by using a Hunter Lab Colourimeter (model Hunter Colour Flex, Reston, USA), with reflectance mode (RSIN), CIE Lab scale $\left(L^{*}, a^{*}\right.$ and $\left.b^{*}\right)$ according to Nielsen (2010). The instrument was calibrated with a standard white ceramic tile and black tile and set up for D65 as illuminant and a $10^{\circ}$ 
observer angle. Reading was made by loading the quartz cuvettes with pulp sample. The loaded cuvettes were exposed to the aperture and readings were recorded. Four readings were obtained for each replicate by changing the position of pulp sample in the optical glass cell to get uniform colour measurements.

Colour was determined using a CIE $L^{*}, a^{*}$ and $b^{*}$ colour system, where $L^{*}$ indicates lightness $\left(\mathrm{L}^{*}=0\right.$, black and $\mathrm{L}^{*}=100$, white $) . a^{*}$ is the chromatic coordinate that represents the proportion of redness and varies from green () to red (+) and $b^{*}$ is the chromatic coordinate that represents the proportion of yellowness and varies from blue (-) to yellow (+). The non-enzymatic browning (NEB) in the pulp was determined by measuring optical density (OD) of methanol extracts of samples at 440 $\mathrm{nm}$ in UV-VIS spectrophotometer (Labomed Incorporated, USA).Browning was observed by taking transmittance of the solution in Spectronic -20 .

The samples for browning were centrifuged for 15 minutes at $4000 \mathrm{rpm}$. For $10 \mathrm{ml}$ of centrifugation $15 \mathrm{ml}$ of alcohol was added to make 60 per cent aqueous solution and kept for half an hour. Then filtered it through Whatman filter paper No.1 to obtain clear solution. Colour was measured at $440 \mathrm{~nm}$ using 60 per cent aqueous alcohol as blank. The increase in absorbance of a sample at 440 nm was taken as a measure of non-enzymatic browning.

\section{Results and Discussion}

\section{Carotenoids}

The total carotenoids content declined regularly during storage of pulp (Table 1). Oxidation of pigments during storage may be responsible for such loss in carotenoids component. The maximum carotenoid content was recorded under treatment $\mathrm{T}_{13}$-frozen storage at $-20^{\circ} \mathrm{C}$ followed by $\mathrm{T}_{12}$ refrigeration at $4 \pm 2{ }^{0} \mathrm{C}$ and lowest in $\mathrm{T}_{7}$-PS@ $0.05 \%$ at 90 days of storage duration. The $L^{*}$ values showed correlation with the carotenoid content of mango pulp. In the present study, lightness seems to be more closely associated with the higher carotenoid content. Further, high carotenoid content at low temperature may be because metabolic pathways that use carotenoids could have been affected by storage at low temperatures. These results are in conformity with Deka et al., (2005), Yahia et al., (2008) and Facundo et al., (2015).

\section{Colour value}

The average $L^{*}, a^{*}$ and $b^{*}$ value of frozen stored mango pulp were 25.51, 12.89 and 2.15 respectively (Tables 2, 3 and 4). These are significantly affected by preservation methods. Average minimum lightness was observed in treatment $\mathrm{T}_{7}$ @ PS@0.05\% (20.11). The lightness and luminosity of stored mango pulp was affected by preservation methods. In none of the treatments negative value for $a^{*}$ (green axis) and $b^{*}$ (blue axis) were observed. Cumulative effect of $L^{*}, a^{*}$ and $b^{*}$ showed that dark colour increased with the advancement of storage duration.

\section{Non enzymatic browning (NEB)}

The NEB of preserved mango pulp increased with the advancement of storage duration (Table 5). Lowest NEB was recorded from treatment $\mathrm{T}_{13}$-frozen storage at $-20^{\circ} \mathrm{C}$ followed by $\mathrm{T}_{12}$-refrigeration at $4 \pm 2{ }^{0} \mathrm{C}$ and highest in $\mathrm{T}_{7}$-PS@ $0.05 \%$. It might be due to formation of furfural and its derivatives at high temperature formed by reaction of ascorbic acid with citric acid. These derivatives could have contributed to nonenzymatic browning which were higher at high temperature. 
Table.1 Effect of different preservatives and temperatures on carotenoids ( $\mathrm{mg} 100 \mathrm{~g}^{-1}$ ) content of Mango pulp during storage

\begin{tabular}{lccccccc}
\hline Treatments & \multicolumn{7}{c}{ Storage duration (days) } \\
\cline { 2 - 8 } & $\mathbf{0}$ & $\mathbf{1 5}$ & $\mathbf{3 0}$ & $\mathbf{4 5}$ & $\mathbf{6 0}$ & $\mathbf{7 5}$ & $\mathbf{9 0}$ \\
\hline $\mathrm{T}_{1}$ (KMS@ 0.05\%) & 5.73 & 5.54 & 5.29 & 5.13 & 5.10 & 4.98 & 4.73 \\
$\mathrm{~T}_{2}$ (KMS@ 0.1\%) & 5.73 & 5.61 & 5.47 & 5.37 & 5.25 & 5.11 & 4.87 \\
$\mathrm{~T}_{3}$ (SB @ 0.05\%) & 5.73 & 5.55 & 5.26 & 5.13 & 5.10 & 4.96 & 4.81 \\
$\mathrm{~T}_{4}$ (SB 0.1\%) & 5.73 & 5.58 & 5.38 & 5.28 & 5.17 & 5.01 & 4.70 \\
$\mathrm{~T}_{5}$ (SMS@ 0.05\%) & 5.73 & 5.42 & 5.14 & 5.13 & 5.10 & 4.97 & 4.81 \\
$\mathrm{~T}_{6}$ (SMS@ 0.1\%) & 5.73 & 5.47 & 5.24 & 5.13 & 5.11 & 4.98 & 4.81 \\
$\mathrm{~T}_{7}$ (PS@ 0.05\%) & 5.72 & 5.43 & 5.14 & 5.11 & 5.01 & 4.88 & 4.72 \\
$\mathrm{~T}_{8}$ (PS@ 0.1\%) & 5.73 & 5.47 & 5.23 & 5.12 & 5.09 & 4.96 & 4.80 \\
$\mathrm{~T}_{9}$ (SB+PS@ 0.05\% each) & 5.73 & 5.54 & 5.28 & 5.16 & 5.10 & 4.98 & 4.85 \\
$\mathrm{~T}_{10}$ (KMS+PS@ 0.05\% each) & 5.73 & 5.56 & 5.35 & 5.23 & 5.12 & 5.00 & 4.80 \\
$\mathrm{~T}_{11}$ (SMS+PS@ 0.05\% each) & 5.73 & 5.53 & 5.26 & 5.22 & 5.09 & 4.96 & 4.82 \\
$\mathrm{~T}_{12}$ (Refrigeration $\left(4 \pm 2{ }^{\circ} \mathrm{C}\right.$ ) & 5.73 & 5.62 & 5.49 & 5.37 & 5.26 & 5.12 & 4.91 \\
$\mathrm{~T}_{13}$ (Frozen storage -20 ${ }^{\circ} \mathrm{C}$ ) & 5.73 & 5.62 & 5.49 & 5.40 & 5.28 & 5.14 & 4.94 \\
SEm \pm & 0.12 & 0.12 & 0.07 & 0.06 & 0.05 & 0.05 & 0.03 \\
C.D. (P=0.05) & NS & NS & 0.20 & 0.16 & 0.15 & 0.14 & 0.09 \\
\hline
\end{tabular}

Table.2 Effect of different preservatives and temperatures on colour $L^{*}$ value content of Mango pulp during storage

\begin{tabular}{|c|c|c|c|c|c|c|c|}
\hline \multirow[t]{2}{*}{ Treatments } & \multicolumn{7}{|c|}{ Storage duration (days) } \\
\hline & $\mathbf{0}$ & 15 & 30 & 45 & 60 & 75 & 90 \\
\hline $\mathrm{T}_{1}$ (KMS@ 0.05\%) & 58.23 & 46.93 & 41.22 & 36.05 & 31.66 & 25.92 & 21.27 \\
\hline $\mathrm{T}_{2}$ (KMS@0.1\%) & 58.65 & 47.84 & 43.75 & 38.42 & 35.78 & 29.65 & 23.75 \\
\hline $\mathrm{T}_{3}(\mathrm{SB} @ 0.05 \%)$ & 59.23 & 46.33 & 39.64 & 35.11 & 29.11 & 25.98 & 23.70 \\
\hline $\mathrm{T}_{4}(\mathrm{SB} @ 0.1 \%)$ & 58.34 & 45.67 & 42.88 & 36.93 & 33.54 & 26.87 & 23.45 \\
\hline $\mathrm{T}_{5}$ (SMS@ 0.05\%) & 59.23 & 45.23 & 39.87 & 35.21 & 29.12 & 25.13 & 23.30 \\
\hline $\mathrm{T}_{6}$ (SMS@ 0.1\%) & 59.32 & 45.76 & 39.97 & 35.37 & 29.67 & 25.72 & 23.70 \\
\hline $\mathrm{T}_{7}$ (PS@ 0.05\%) & 59.12 & 45.03 & 42.78 & 37.72 & 31.65 & 25.76 & 20.11 \\
\hline $\mathrm{T}_{8}(\mathrm{PS} @ 0.1 \%)$ & 59.12 & 45.11 & 42.81 & 37.76 & 31.69 & 25.82 & 20.17 \\
\hline $\mathrm{T}_{9}$ (SB+PS@0.05\% each) & 58.83 & 45.67 & 42.13 & 36.77 & 32.25 & 24.35 & 20.15 \\
\hline $\mathrm{T}_{10}(\mathrm{KMS}+\mathrm{PS} @ 0.05 \%$ each$)$ & 58.72 & 46.13 & 39.82 & 34.67 & 32.84 & 26.67 & 22.65 \\
\hline $\mathrm{T}_{11}$ (SMS+PS@0.05\% each) & 58.66 & 46.87 & 40.34 & 35.21 & 32.10 & 25.23 & 22.45 \\
\hline $\mathrm{T}_{12}$ (Refrigeration $\left(4 \pm 2{ }^{\circ} \mathrm{C}\right)$ & 58.23 & 51.10 & 46.23 & 40.79 & 35.89 & 29.71 & 24.21 \\
\hline $\mathrm{T}_{13}$ (Frozen storage $-20{ }^{\circ} \mathrm{C}$ ) & 58.43 & 52.28 & 46.76 & 41.22 & 35.93 & 29.78 & 25.51 \\
\hline SEm \pm & 1.25 & 1.57 & 1.74 & 1.51 & 0.72 & 0.48 & 0.52 \\
\hline C.D. $(\mathrm{P}=0.05)$ & NS & NS & NS & NS & 2.10 & 1.39 & 1.52 \\
\hline
\end{tabular}

Table.3 Effect of different preservatives and temperatures on colour $a^{*}$ value of Mango pulp during storage

\begin{tabular}{lccccccc}
\hline Treatments & \multicolumn{7}{c}{ Storage duration (days) } \\
\cline { 2 - 8 } & $\mathbf{0}$ & $\mathbf{1 5}$ & $\mathbf{3 0}$ & $\mathbf{4 5}$ & $\mathbf{6 0}$ & $\mathbf{7 5}$ & $\mathbf{9 0}$ \\
\hline $\mathrm{T}_{1}$ (KMS@ 0.05\%) & 11.15 & 11.82 & 12.11 & 12.31 & 12.64 & 13.14 & 13.36 \\
$\mathrm{~T}_{2}$ (KMS@ 0.1\%) & 11.13 & 11.66 & 11.93 & 12.16 & 12.38 & 12.86 & 13.06 \\
$\mathrm{~T}_{3}$ (SB@ 0.05\%) & 11.16 & 11.81 & 12.13 & 12.39 & 12.71 & 13.18 & 13.41 \\
$\mathrm{~T}_{4}$ (SB @ 0.1\%) & 11.14 & 11.68 & 11.96 & 12.19 & 12.42 & 12.93 & 13.13 \\
$\mathrm{~T}_{5}$ (SMS@ 0.05\%) & 11.16 & 11.80 & 12.14 & 12.37 & 12.69 & 12.83 & 13.32 \\
$\mathrm{~T}_{6}$ (SMS@ 0.1\%) & 11.15 & 11.78 & 12.13 & 12.36 & 12.64 & 12.82 & 13.29 \\
$\mathrm{~T}_{7}$ (PS@ 0.05\%) & 11.16 & 11.89 & 12.21 & 12.39 & 12.73 & 13.23 & 13.46 \\
$\mathrm{~T}_{8}$ (PS@ 0.1\%) & 11.15 & 11.84 & 12.16 & 12.35 & 12.67 & 13.17 & 13.37 \\
$\mathrm{~T}_{9}$ (SB+PS@ 0.05\% each) & 11.13 & 11.77 & 12.07 & 12.29 & 12.56 & 13.03 & 13.21 \\
$\mathrm{~T}_{10}$ (KMS+PS@ 0.05\% each) & 11.14 & 11.73 & 12.01 & 12.21 & 12.48 & 12.99 & 13.18 \\
$\mathrm{~T}_{11}$ (SMS+PS@ 0.05\% each) & 11.15 & 11.78 & 12.09 & 12.27 & 12.59 & 13.09 & 13.29 \\
$\mathrm{~T}_{12}$ (Refrigeration $\left(4 \pm 2{ }^{\circ} \mathrm{C}\right.$ ) & 11.13 & 11.62 & 11.89 & 12.11 & 12.32 & 12.78 & 12.98 \\
$\mathrm{~T}_{13}$ (Frozen storage -20 ${ }^{\circ} \mathrm{C}$ ) & 10.13 & 10.56 & 11.13 & 11.76 & 12.02 & 12.65 & 12.89 \\
SEm & 0.24 & 0.26 & 0.30 & 0.10 & 0.13 & 0.12 & 0.08 \\
C.D. (P=0.05) & NS & NS & NS & 0.30 & 0.38 & 0.35 & 0.25 \\
\hline
\end{tabular}


Table.4 Effect of different preservatives and temperatures on colour $b^{*}$ value content of Mango pulp during storage

\begin{tabular}{|c|c|c|c|c|c|c|c|}
\hline \multirow{2}{*}{ Treatments } & \multicolumn{7}{|c|}{ Storage duration (days) } \\
\hline & $\mathbf{0}$ & 15 & 30 & 45 & 60 & 75 & 90 \\
\hline $\mathrm{T}_{1}(\mathrm{KMS} @ 0.05 \%)$ & 15.32 & 12.78 & 10.73 & 8.30 & 6.37 & 4.63 & 2.66 \\
\hline $\mathrm{T}_{2}(\mathrm{KMS} @ 0.1 \%)$ & 15.32 & 13.21 & 11.30 & 9.67 & 6.50 & 4.57 & 2.51 \\
\hline $\mathrm{T}_{3}(\mathrm{SB} @ 0.05 \%)$ & 15.20 & 12.91 & 10.79 & 8.75 & 6.34 & 4.77 & 2.72 \\
\hline $\mathrm{T}_{4}(\mathrm{SB} @ 0.1 \%)$ & 15.31 & 13.18 & 11.17 & 9.28 & 6.30 & 4.71 & 2.71 \\
\hline $\mathrm{T}_{5}(\mathrm{SMS} @ 0.05 \%)$ & 15.31 & 12.23 & 10.28 & 8.77 & 6.25 & 5.67 & 2.61 \\
\hline $\mathrm{T}_{6}$ (SMS@0.1\%) & 15.31 & 12.43 & 10.52 & 8.00 & 6.22 & 4.55 & 2.53 \\
\hline $\mathrm{T}_{7}(\mathrm{PS} @ 0.05 \%)$ & 15.41 & 12.16 & 10.17 & 8.14 & 6.55 & 4.88 & 2.88 \\
\hline $\mathrm{T}_{8}(\mathrm{PS} @ 0.1 \%)$ & 15.30 & 12.23 & 10.28 & 8.32 & 6.48 & 4.70 & 2.78 \\
\hline $\mathrm{T}_{9}(\mathrm{SB}+\mathrm{PS} @ 0.05 \%$ each) & 15.36 & 12.79 & 10.57 & 8.78 & 6.68 & 4.55 & 2.57 \\
\hline $\mathrm{T}_{10}(\mathrm{KMS}+\mathrm{PS} @ 0.05 \%$ each $)$ & 15.21 & 12.98 & 11.66 & 8.56 & 6.78 & 4.78 & 2.52 \\
\hline $\mathrm{T}_{11}$ (SMS+PS@ 0.05\% each) & 15.22 & 12.73 & 10.51 & 8.52 & 6.77 & 4.92 & 2.56 \\
\hline $\mathrm{T}_{12}$ (Refrigeration $\left(4 \pm 2{ }^{\circ} \mathrm{C}\right)$ & 15.38 & 13.31 & 11.28 & 9.44 & 6.36 & 4.52 & 2.48 \\
\hline $\mathrm{T}_{13}$ (Frozen storage $\left.-20{ }^{\circ} \mathrm{C}\right)$ & 15.37 & 13.54 & 11.26 & 9.32 & 6.31 & 4.42 & 2.15 \\
\hline SEm \pm & 0.21 & 0.52 & 0.43 & 0.36 & 0.11 & 0.09 & 0.06 \\
\hline C.D. $(\mathrm{P}=0.05)$ & NS & NS & NS & NS & 0.31 & 0.26 & 0.19 \\
\hline
\end{tabular}

Table.5 Effect of different preservatives and temperatures on NEB (440 nm) of Mango pulp during storage

\begin{tabular}{|c|c|c|c|c|c|c|c|}
\hline \multirow[t]{2}{*}{ Treatments } & \multicolumn{7}{|c|}{ Storage duration (days) } \\
\hline & $\mathbf{0}$ & 15 & 30 & 45 & 60 & 75 & 90 \\
\hline T & 0.02 & 0.03 & 0.06 & 0.09 & 0.12 & 0.19 & 0.24 \\
\hline $\mathrm{T}_{2}(\mathrm{KMS} @ 0.1 \%)$ & 0.02 & 0.03 & 0.06 & 0.08 & 0.12 & 0.19 & 0.23 \\
\hline $\mathrm{T}_{3}(\mathrm{SB} @ 0.05 \%)$ & 0.02 & 0.04 & 0.06 & 0.09 & 0.13 & 0.19 & 0.24 \\
\hline $\mathrm{T}_{4}(\mathrm{SB} @ 0.1 \%)$ & 0.02 & 0.03 & 0.06 & 0.08 & 0.12 & 0.18 & 0.23 \\
\hline $\mathrm{T}_{5}(\mathrm{SMS} @ 0.05 \%)$ & 0.02 & 0.04 & 0.06 & 0.08 & 0.13 & 0.19 & 0.24 \\
\hline $\mathrm{T}_{6}$ (SMS@0.1\%) & 0.02 & 0.04 & 0.06 & 0.08 & 0.13 & 0.19 & 0.24 \\
\hline $\mathrm{T}_{7}$ (PS@0.05\%) & 0.02 & 0.03 & 0.06 & 0.09 & 0.13 & 0.20 & 0.29 \\
\hline $\mathrm{T}_{8}(\mathrm{PS} @ 0.1 \%)$ & 0.02 & 0.03 & 0.06 & 0.08 & 0.13 & 0.20 & 0.28 \\
\hline T 9 (SB+PS@ 0.05\% each) & 0.02 & 0.03 & 0.06 & 0.08 & 0.12 & 0.20 & 0.27 \\
\hline $\mathrm{T}_{10}(\mathrm{KMS}+\mathrm{PS} @ 0.05 \%$ each $)$ & 0.02 & 0.03 & 0.06 & 0.09 & 0.12 & 0.19 & 0.24 \\
\hline $\mathrm{T}_{11}(\mathrm{SMS}+\mathrm{PS} @ 0.05 \%$ each $)$ & 0.02 & 0.03 & 0.06 & 0.08 & 0.13 & 0.19 & 0.24 \\
\hline $\mathrm{T}_{12}$ (Refrigeration $\left(4 \pm 2{ }^{\circ} \mathrm{C}\right)$ & 0.02 & 0.03 & 0.06 & 0.08 & 0.12 & 0.19 & 0.22 \\
\hline $\mathrm{T}_{13}$ (Frozen storage $-20^{\circ} \mathrm{C}$ ) & 0.02 & 0.03 & 0.06 & 0.08 & 0.11 & 0.19 & 0.21 \\
\hline $\mathrm{SEm} \pm$ & 0.000 & 0.002 & 0.001 & 0.001 & 0.001 & 0.002 & 0.002 \\
\hline C.D. $(P=0.05)$ & NS & NS & 0.002 & 0.003 & 0.004 & 0.005 & 0.005 \\
\hline
\end{tabular}

Low non-enzymatic browning in treatment $\mathrm{T}_{2}$ -KMS@ $0.1 \%$ might be due to better antioxidant action of KMS and more nonenzymatic browning in $\mathrm{T}_{7}$ PS@ $0.05 \%$ could be due to Maillard and Caramelization reactions. The reaction of organic acids with sugar or oxidation of phenols leads to the formation of brown pigment which causes non enzymatic browning.

The present results of browning are in agreement with Yadav et al., (2017) who reported lowest NEB at frozen storage at - $20^{\circ} \mathrm{C}$ of guava pulp probably due to lower rate of oxidation activities at low temperature. A linear increase in browning of stored guava nectar was also observed by Barmanray et al., (1995). Loss of sulphur di- oxide and ascorbic acid also indicated the chances of increased browning.

Thus mango pulp preservation under low temperature $\left(-20^{\circ} \mathrm{C}\right.$ and $\left.4 \pm 2^{\circ} \mathrm{C}\right)$ gave superior quality in terms of good colour, and least browning and highest carotenoid content during the storage, frozen storage at $-20^{\circ} \mathrm{C}$ 
was found best from health point of view as compared to the chemical preservatives and may be recommended for the storage of mango pulp and use it further for making different value added products viz., squash, RTS and jam as the quality of products made from frozen pulp was best among all the samples.

\section{References}

Barmanray, A., Gupta, O.P. and Dhawan, S.S.1995. Evaluation of guava (Psidium guajava L.) hybrids for making nectar. Haryana Journal of Horticulture Science, 24(4): 102-109.

Deka, B.C., Sethi, V. and Saikia, A. 2005. Changes in quality of mango-pineapple spiced beverage during storage. Indian Journal of Horticulture, 62: 71-75.

Facundo, H., Gurak, P.D., Mercadante, A.Z. and Cordenunsi, B.R. 2015.Storage at low temperature differentially affects the colour and carotenoid composition of two cultivars of banana. Food Chemistry, 170: 102-109.

Hussain, S., Rehman, S., Randhawa, M.A. and Iqbal, M. 2003. Studies on physiochemical, microbiological and sensory evaluation of mango pulp storage with chemical preservatives. Journal of Research (Science), 14(1): 01-09.

Nielsen, S.S. 2010. Food Analysis Laboratory Manual Springer, New York. pp: 1-177

Saxena, M., Bhattacharya, S. and Malhotra, S.K. 2015. Horticultural statistics at a glance 2015. Oxford university press, New Delhi, p.186.

Sivakumar, D., Jiang, Y. and Yahia, E.M. 2011. Maintaining mango (Mangifera indica L.) fruit quality during the export chain. Food Research International, 44(5): 1254-1263.

Tharanathan, R.N., Yashoda, H. M. and Prabha, T. N. 2006. Mango (Mangifera indica L.), the king of fruits-An overview. Food Reviews International, 22(2): 62-65.

Thimmiah, S.R. 1999. Estimation of carotene content. Standard Method of Biochemical Analysis. Kalyani Publisher, New Delhi, pp: 304-305.

Yadav, S.K., Sarolia, D.K., Pilania, S., Meena, H.R. and Mahawer, L.N. 2017. Studies on keeping quality of preserved guava pulp during storage. International Journal of Current Microbiology and Applied Sciences, 6(3): 1235-1242.

\section{How to cite this article:}

Manisha Jangir, Virendra Singh and Disha Kala. 2017. Studies on Carotenoid Content, Colour and Browning of Physio-Chemically Stored Mango (Mallika) Pulp for Processed Products. Int.J.Curr.Microbiol.App.Sci. 6(8): 1997-2002. doi: https://doi.org/10.20546/ijcmas.2017.608.238 